\title{
Reactivity-Selectivity Principle: Phenyl Group in Indazole Makes It More Lucid
}

\author{
R. Sanjeev ${ }^{1}$ and V. Jagannadham ${ }^{2 *}$ \\ Corresponding author: jagannadham1950@yahoo.com \\ ${ }^{1}$ Department of Chemistry, Geethanjali College of Engineering and Technology, \\ Cheeryal-501301, Telangana, India \\ and \\ ${ }^{2}$ Department of Chemistry, Osmania University, Hyderabad-500007, India
}

\begin{abstract}
:
Linear free energy relationship (LFER) plots are constructed for the deprotonation equilibriums ( $\mathrm{p} K_{\mathrm{aH}+}$ ) of pyrazolium and indazolium (benzopyrazolium) cations. The reaction constants Taft $\rho^{*}$ and Hammett $\rho$ are found to be 2.75 and 1.32 for deprotonation $\left(\mathrm{p} K_{\mathrm{aH}+}\right)$ of pyrazolium and indazolium cations respectively. Higher value of Taft $\rho^{*}$ than the Hammett $\rho$ is explained in terms of extra stability of the indazolium cation due to its greater number of resonance structures. This article is an exercise to undergraduate students for writing different resonance structures of indazolium cation.
\end{abstract}

\section{Keywords:}

Reactivity-Selectivity Principle; Taft equation; Hammett equation

\section{Introduction:}

It was found that there was a linear correlation between the half-wave oxidation potentials $\mathrm{E}_{1 / 2}$ of the pentacyano (L) ferrates (II) complexes, where L refers to various substituted pyrazoles and indazoles, and $\mathrm{p} K_{\mathrm{aH}+}$ of pyrazolium and indazolium cations respectively [1]. In the present article the $\mathrm{p} K_{\mathrm{aH}+}$ data of pyrazolium and indazolium cations is used to make Taft and Hammett plots and using the Taft $\rho^{*}$ and Hammett $\rho$ values the Reactivity-Selectivity Principle is explained in a simple and lucid way.

\section{Methods:}

All correlations were done using KaleidaGraph software, Reading, PA, USA. All the chemical structures were drawn using chemdraw. The $\mathrm{p} K_{\mathrm{aH}^{+}}$data is from reference 1 . Reaction constants (Hammett $\rho$ and Taft $\rho^{*}$ ) are to be understood as positive values. The loci of the plots in this article are with negative slopes because the $\mathrm{p} K_{\mathrm{aH}}+$ data is plotted against the substituent constants (Hammett $\sigma$ and Taft $\sigma^{*}$ ).

\section{Discussion:}

Pyrazole is a five-membered aromatic ring containing two adjacent nitrogens. The pyrrole-type nitrogen with a lone pair of electrons involved in aromaticity of the pyrazole ring. The other 
pyridine-type sp2- hybridized nitrogen has its lone pair away and out of the plane from the ring structure [2]. Hence the preferential protonation of pyrazole would be at N(2)-nitrogen. The resonance structures of protonated pyrazole (pyrazolium cation) are shown in scheme 1.

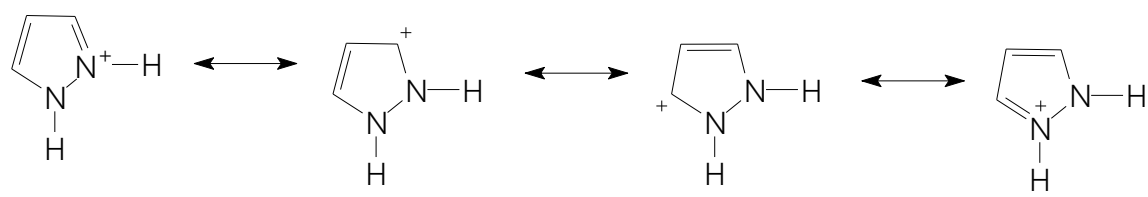

Scheme 1

Similarly, the resonance structures of indazolium cation are shown in scheme 2.

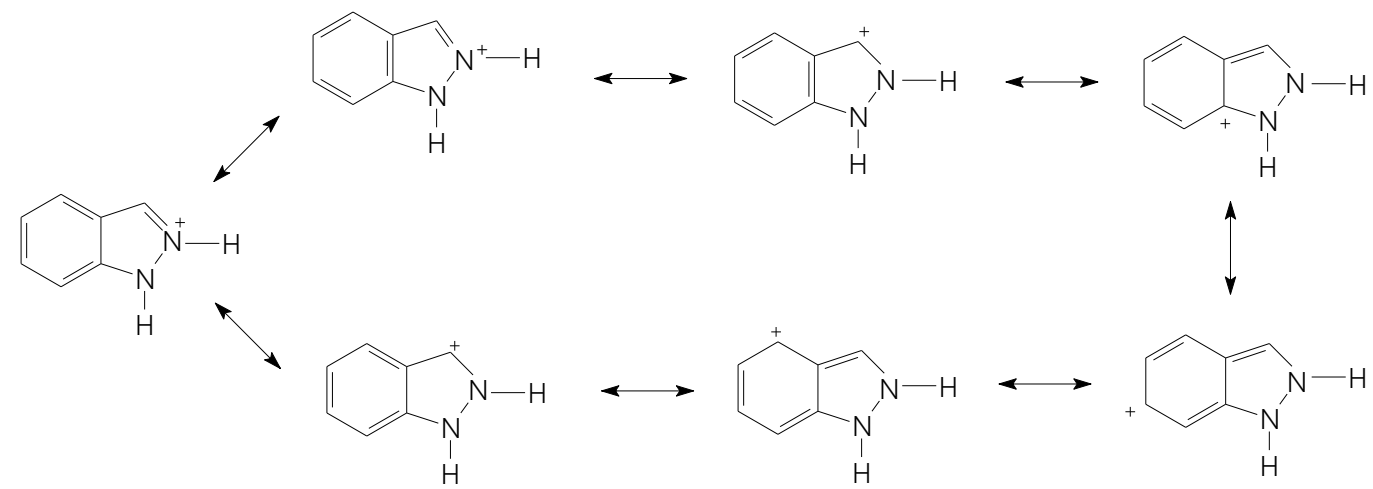

Scheme 2

The $\mathrm{p} K_{\mathrm{aH}+}$ data of pyrazolium and indazolium cations is given in table 1 .

Table 1: $\mathrm{p} K_{\mathrm{aH}+}$ data of Pyrazolium and Indazolium (Benzopyrazolium) cations

\begin{tabular}{|c|c|c|c|c|c|c|c|c|}
\hline & $\mathrm{N}_{2}^{+}{ }_{2}^{+-H}$ & ${ }_{5}^{4} \prod_{\substack{N_{1} \\
H}}^{3} N_{2}^{3}$ & $+\mathrm{H}^{+}$ & & 3 & & $\begin{array}{l}N_{1} \\
\mathrm{H}_{1} \\
\mathrm{H}\end{array}$ & $+\quad \mathrm{H}^{+}$ \\
\hline \multirow[t]{2}{*}{$\begin{array}{l}\text { Sl. } \\
\text { No. }\end{array}$} & \multicolumn{2}{|c|}{$\begin{array}{c}\mathrm{H}_{1} \\
\text { Pyrazole } \\
\end{array}$} & \multirow[t]{2}{*}{$\begin{array}{l}\mathrm{E}_{1 / 2} \mathrm{mV}, \\
\mathrm{vs} \mathrm{SCE}\end{array}$} & \multirow[t]{2}{*}{$\mathrm{p} K_{\mathrm{aH}+}$} & Inda & $\begin{array}{l}\mathrm{H} \\
\text { ole }\end{array}$ & \multirow[t]{2}{*}{$\begin{array}{l}\mathrm{E}_{1 / 2} \mathrm{mV} \text {, } \\
\text { vs SCE }\end{array}$} & \multirow[t]{2}{*}{$\mathrm{p} K_{\mathrm{aH}+}$} \\
\hline & substituent & $\begin{array}{c}\text { Hammett } \sigma / \\
\text { Taft } \sigma^{*}\end{array}$ & & & substituent & $\begin{array}{c}\text { Hammett } \\
\sigma \\
\end{array}$ & & \\
\hline 1 & $\mathrm{H}$ & 0.49 & 198 & 2.64 & $\mathrm{H}$ & 0.00 & 254 & 1.39 \\
\hline 2 & 3-Me & 0.00 & 148 & 3.73 & $4-\mathrm{NO}_{2}$ & 0.71 & 292 & 0.42 \\
\hline 3 & $4-\mathrm{Cl}$ & 0.37 & 225 & 2.03 & $5-\mathrm{NO}_{2}$ & 0.80 & 304 & 0.13 \\
\hline 4 & 3,5-diMe & -0.17 & 125 & 4.55 & $6-\mathrm{NO}_{2}$ & 0.80 & 282 & 0.66 \\
\hline 5 & & & & & $5,6-\mathrm{diNO}_{2}$ & 1.60 & 340 & -0.73 \\
\hline
\end{tabular}


The Taft plot for deprotonation equilibrium of pyrazolium cation is shown as in figure 1 .

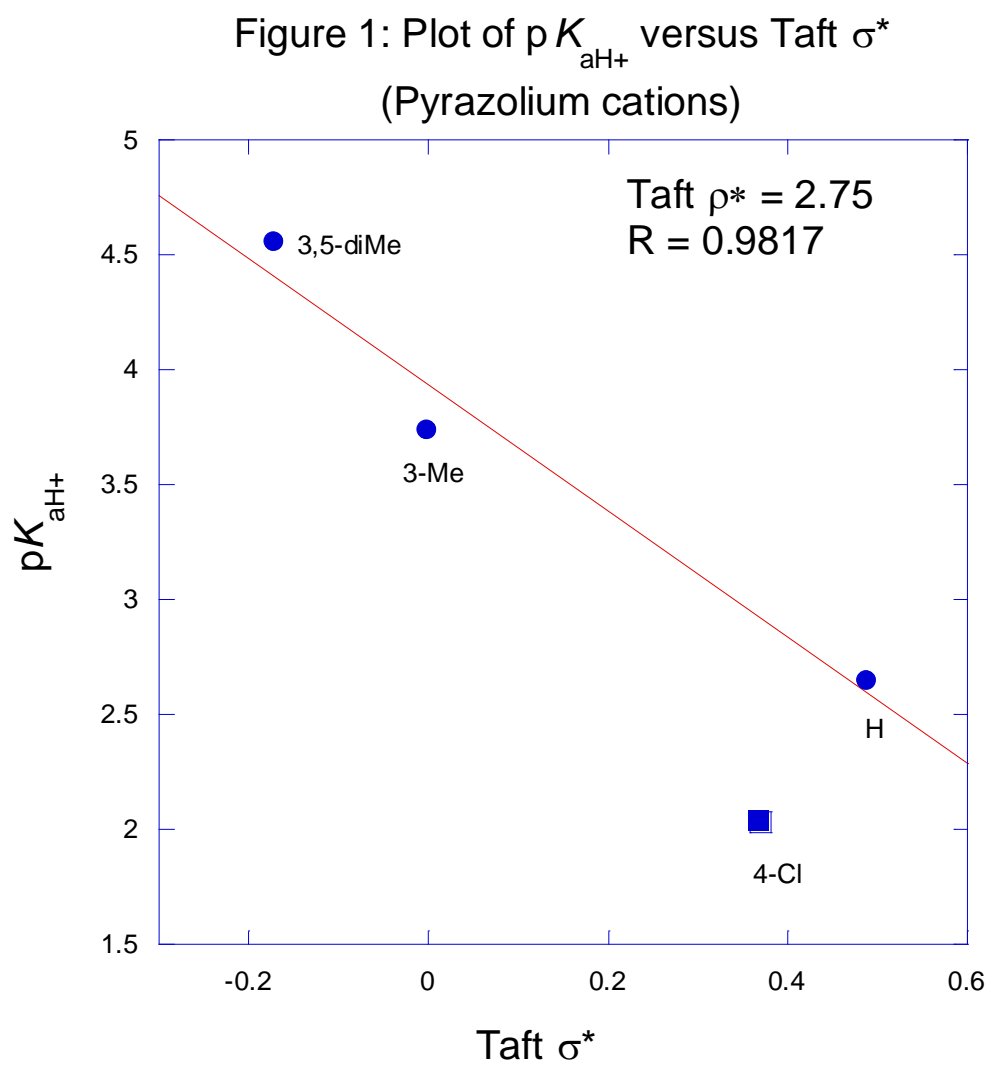

The substituent constants in pyrazolium moiety are assigned based on the following arguments.

In scheme 3, structure $\mathbf{A}$ is the depiction of the benzene derivative with substituents at ortho, meta and para positions to FG.

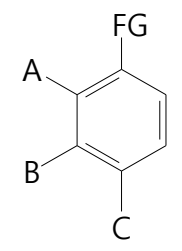

A

Scheme 3

In $\mathbf{A}, \mathrm{FG}=$ functional group, $\mathrm{A}, \mathrm{B}$ and $\mathrm{C}$ are substituents at ortho, meta and para positions respectively. The structure of pyrazolium cation is shown as in scheme 4 .

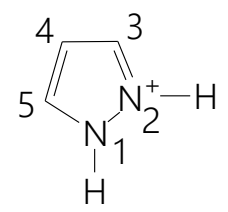

Scheme 4: Pyrazolium cation 
Position 3 in pyrazolium cation would be ortho to $\mathrm{N}^{+}(2)-\mathrm{H}$ nitrogen comparing it with the structure $\boldsymbol{A}$ of the benzene ring. Position 4 would be meta to $\mathrm{N}^{+}(2)-\mathrm{H}$ nitrogen. And position 5 would be para. Therefore, the substituent constants in pyrazolium moiety given in table 1 are justified. The substituent constant of 3,5-dimethyl is taken as -0.17 because the Taft $\sigma^{*}$ value of 3-methyl group would be zero which is ortho to $\mathrm{N}^{+}(2)$ position and that of 5-methyl group is -0.17 which is considered as para substituent via the carbons 3 and 4 . One can argue that the 5-methyl group is to be considered as meta to nitrogen at position 2 via nitrogen at position 1 . This may not be possible because the reaction site that is the deprotonation site of nitrogen at position 3 is not in conjugation with carbon at position 5. They are separated by two single bonds which may act as insulators for any effect to be transmitted shown by 5-methyl group on the deprotonation from the nitrogen at position 3. Therefore the 5-methyl group is considered as para to the deprotonation site via the carbons 3 and 4 since they are in conjugation with two $\pi$ bonds which in turn can transmit substituent effect. Deviation of 4-Cl from the correlation is not explainable at present.

The Hammett plot for deprotonation equilibrium of indazolium cation is shown as in figure 2.

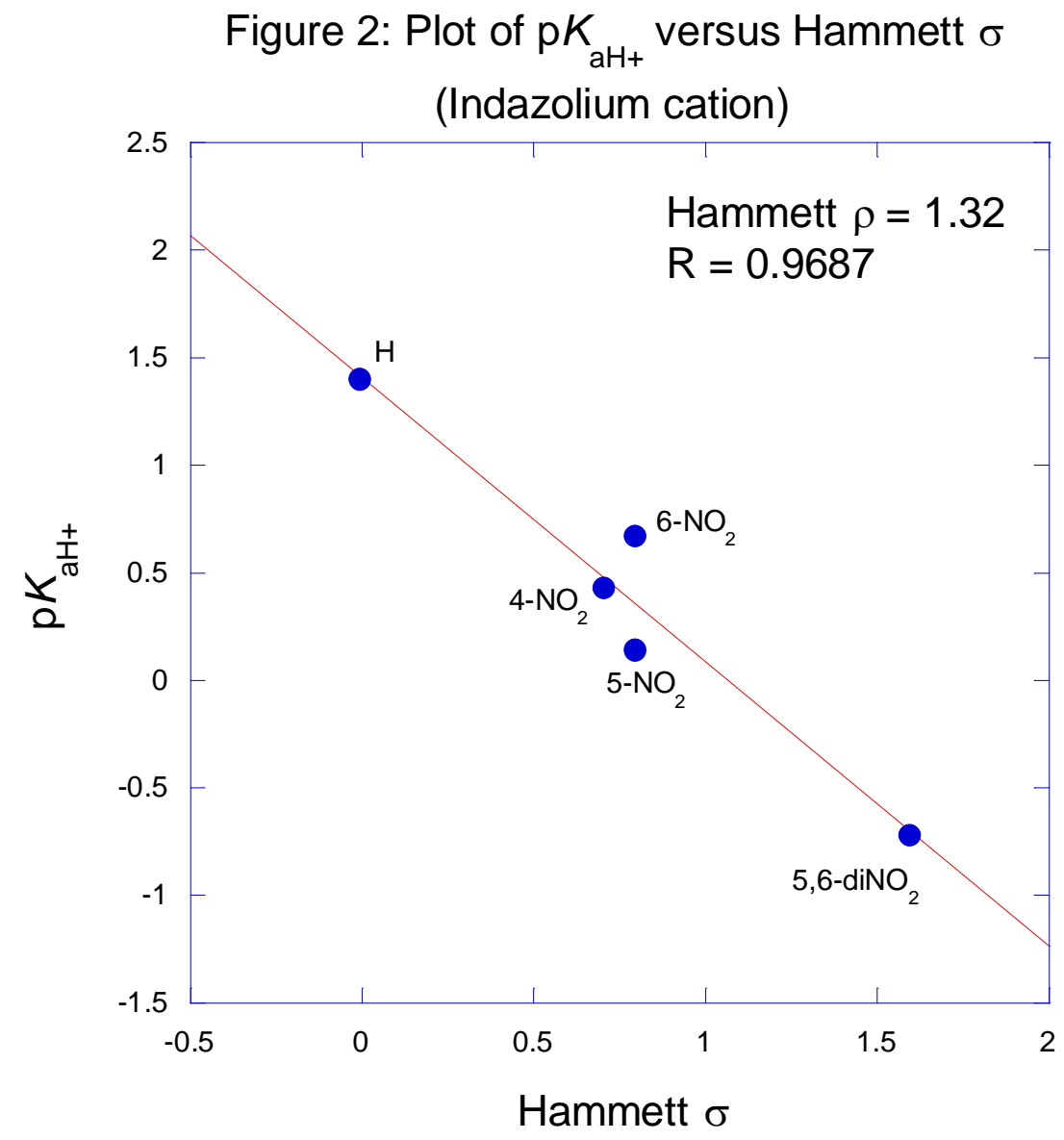


The structure of indazolium cation is shown as in scheme 5 .<smiles></smiles>

Scheme 5: Indazolium cation

Again, the substituent constants in indazolium moiety are assigned based on the following arguments comparing it with structure $\mathbf{A}$.

4- $\mathrm{NO}_{2}$ group is taken as meta to the $\mathrm{N}^{+}(2)-\mathrm{H}$ nitrogen. 5- $\mathrm{NO}_{2}, 6-\mathrm{NO}_{2}$ and 5,6-di $\mathrm{NO}_{2}$ are taken as para to the $\mathrm{N}^{+}(2)-\mathrm{H}$ nitrogen.

The same trend is expected with the half-wave potentials of pyrazoles and indazoles because the $\mathrm{p} K_{\mathrm{aH}+}$ and the half-wave potentials are related to each other by the eqn. $\mathrm{E}_{1 / 2}(\mathrm{mV}, \mathrm{vs} \mathrm{SCE})$ $=-m \bullet p K_{\mathrm{a}}+$ constant [1]. The plots are as shown in figure 3 and 4.

Figure 3: Plot of $E_{1 / 2}\left(m V\right.$ vs SCE) versus Taft $\sigma^{*}$ (Pyrazolium cations)

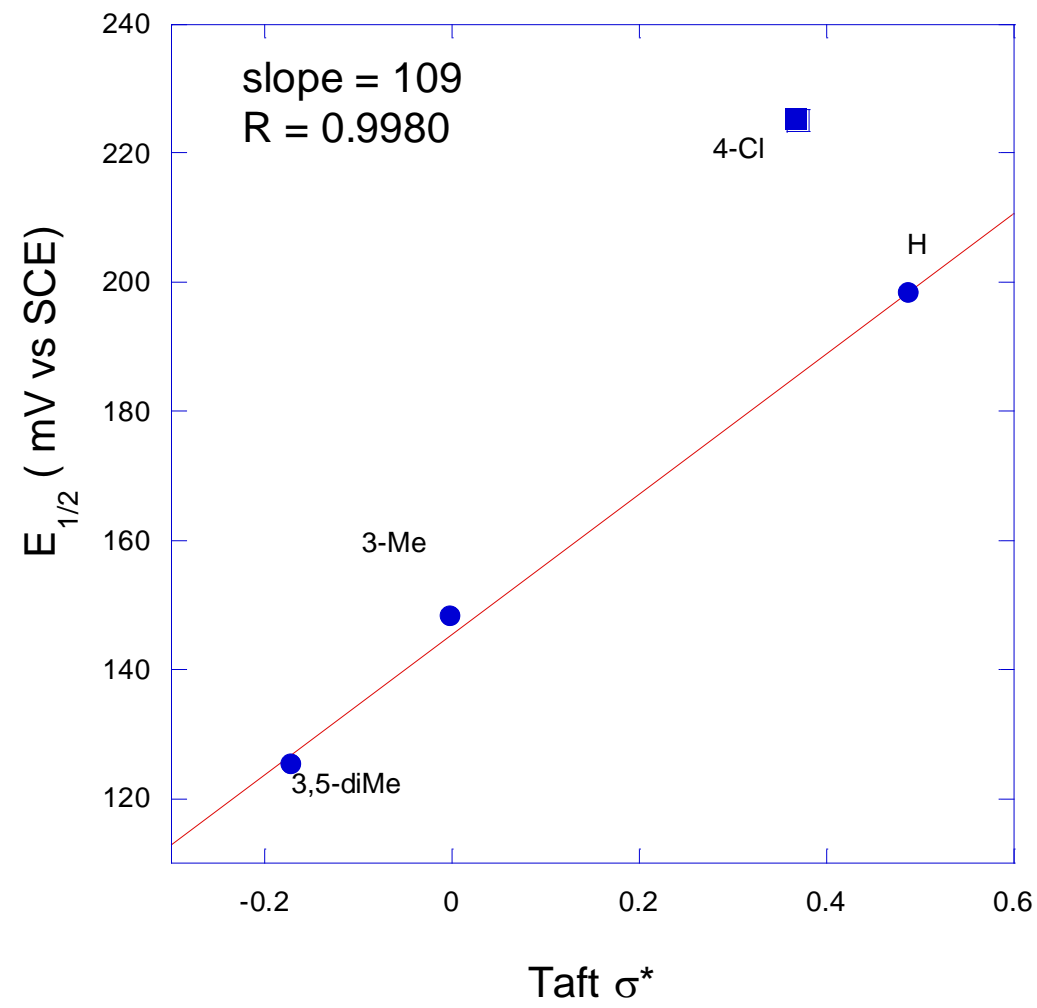




\section{Figure 4: Plot of $\mathrm{E}_{1 / 2}$ (mV vs SCE) versus Hammett $\sigma$} (Indazolium cations)

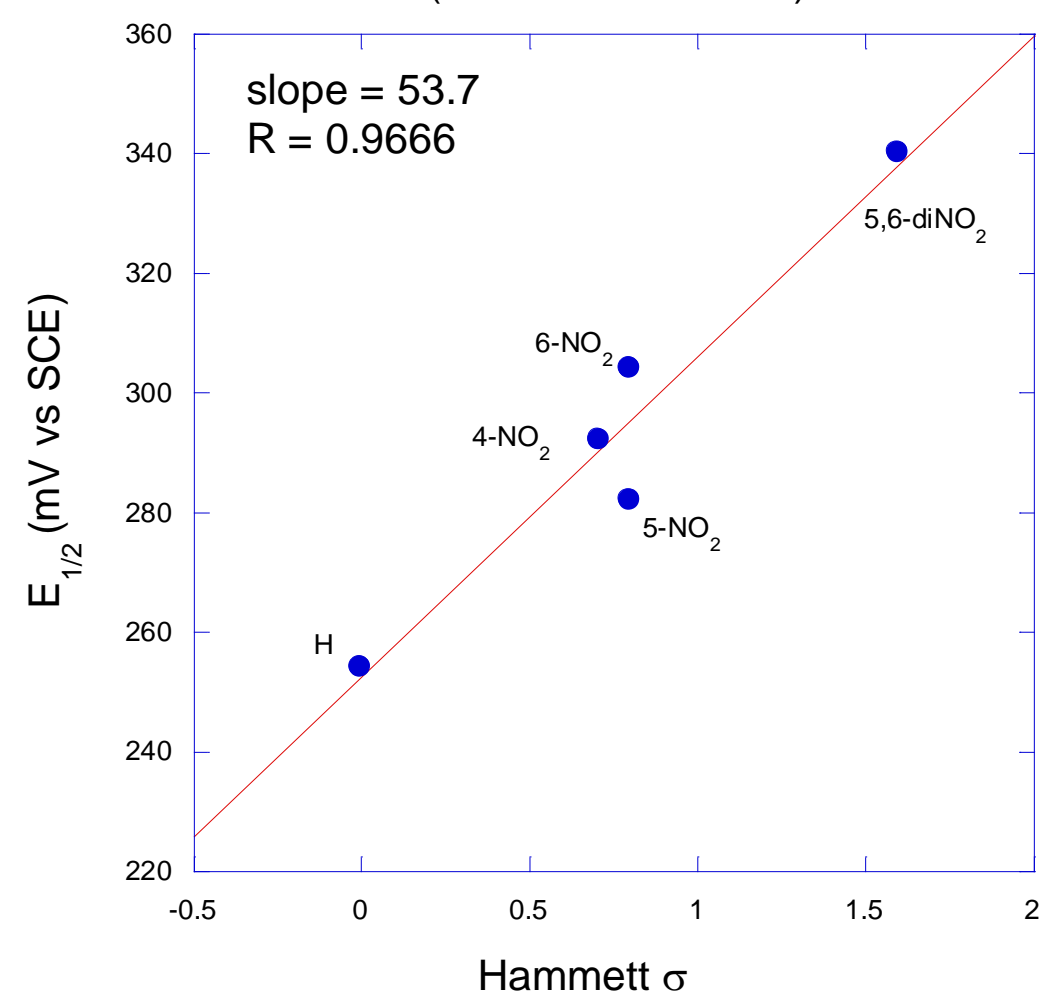

From the Taft and Hammett plots it is seen that the Taft $\rho^{*}$ value 2.75 is larger than Hammett $\rho$ value 1.32. Here the comparison of Taft and Hammett reaction constants ( $\rho^{*}$ and $\rho$ ) need not be misunderstood by the readers because in the evaluation of Taft $\sigma^{*}$ values a factor of 2.48 is used to divide the difference of logarithm of base and acid catalyzed rate constants of ethyl acetate and substituted ethyl acetates [3] to keep the Taft substituent constants $\sigma^{*}$ on the Hammett scale. The equation used is:

$$
\sigma^{*}=\frac{1}{2.48}\left[\log \left(\frac{k}{k_{\mathrm{O}}}\right)_{\mathrm{B}}-\log \left(\frac{k}{k_{\mathrm{O}}}\right)_{\mathrm{A}}\right]
$$

The factor 2.48 is the mean value of the Hammett reaction constants $[4,5] \rho_{\mathrm{B}}$ for base-catalyzed hydrolysis ( $\mathrm{B}_{\mathrm{Ac}} 2$ mechanism: bimolecular, base catalyzed, acyl oxygen fission) of meta and para substituted ethyl and methyl benzoates in different solvents and at different temperatures. From the schemes 1 and 2, the indazolium cation has a greater number of resonance structures leading to its larger stability than the pyrazolium cation.

The larger Taft $\rho^{*}$ value of 2.75 than the value of Hammett $\rho 1.32$ indicates that the less stable pyrazolium cation is more susceptible to substituent effect and more stable indazolium cation 
is less susceptible to substituent effect. And similarly, the slope 109 of $\mathrm{E}_{\frac{1}{2} / 2}(\mathrm{mV}$, vs SCE) versus Taft $\sigma^{*}$ for pyrazolium cation is larger than that of 54 of indazolium cation. These two observations lead to invoke the reactivity-selectivity principle.

\section{Conclusion:}

Pyrazole and Indazole on protonation of nitrogen at position 3 yields pyrazolium cation and indazolium cation respectively without losing their aromaticity. Phenyl group in indazole contributes larger number of resonance structures (scheme 2) makes the indazolium cation more stable than the pyrazolium cation with a smaller number of resonance structures (scheme 1). This makes the indazolium cation less susceptible toward substituent effect on the deprotonation equilibrium. Also, the present article is a good chemical education exercise to undergraduate students for writing the resonance structures of pyrazolium cation. 


\section{References:}

1. Jean-Louis Brisset and Victor Ilimbi, Can. J. Chem, Vol. 58, 1980, page 1250

2. Giller, S.A.; Mazheika, I.B.; Grandberg, I.I. Electron density distribution in heterocyclic systems with two vicinal nitrogen atoms. II. Pyrazole dipole moments. Khimiya Geterotsiklicheskikh Soedin. 1965, 1, 103-106.

3. V. Jagannadham and R. Sanjeev, Physical Chemistry, 2012, 2(6): 100-102 DOI: 10.5923/j.pc.20120206.03, Open Access Link: http://article.sapub.org/10.5923.j.pc. 20120206.03.html

4. Neil S. Issacs, "Physical Organic Chemistry", ELBS/Longman, 1987, page 154 and 297.

5. Colin D. Johnson, "The Hammett equation", (Cambridge Texts in Chemistry and Biochemistry) 1980, page 75 